\title{
Street Design and Human Behaviour Factors towards a Safe Urban Environment for Women
}

\author{
Norhafizah Abdul Rahman'1, Maimon Ali², Izham Ghani ${ }^{1}$ \\ 1 Department of Landscape Architecture, ${ }^{2}$ Department of Town and Regional Planning, \\ Faculty of Architecture, Planning \& Surveying, \\ Universiti Teknologi MARA, Malaysia
}

norha776@uitm.edu.my, maimon078@uitm.edu.my, izham025@uitm.edu.my

\begin{abstract}
Integrating women safety in the urban street environment is critical in creating good quality living to improve living standard. This paper discusses women's needs and characteristics of urban streets that can affect women's behaviour. The objectives of this paper are to identify the characters of urban environment in making streets safe for women and establishing the characteristics of safe urban street environment for women. This study is conducted using mixed methodology to identify the relationship between urban street design and women's behaviour. This paper will contribute towards safe urban street design with an excellent urban environment and dynamic economic activities.
\end{abstract}

Keywords: women safety; urban design; safe cities; behavioural study

eISSN: 2398-4295 @ 2019. The Authors. Published for AMER, ABRA \& cE-Bs by e-International Publishing House, Ltd., UK. This is an open access article under the CC BY-NC-ND license (http://creativecommons.org/licenses/bync-nd/4.0/). Peer-review under responsibility of AMER (Association of Malaysian Environment-Behaviour Researchers), ABRA (Association of Behavioural Researchers on Asians) and cE-Bs (Centre for EnvironmentBehaviour Studies), Faculty of Architecture, Planning \& Surveying, Universiti Teknologi MARA, Malaysia.

DOI: http://dx.doi.org/10.21834/ajbes.v4i17.184 


\subsection{Introduction}

Women experience the city differently than men. Urban development will remain elusive without integrating women safety, comfort, convenience and affordability in the urban environment. Urban environment issues have become an important topic globally that has human concentration, and the urbanization process has led to an increase in the urban population and led to increasing attention concerning the quality of urban open spaces that fulfil the users' needs. There is a paucity of studies that link the urban commercial street environment to women behaviour in Malaysia context. This paper discusses women needs in the urban street and the supportive characteristics of urban spaces that can affect women behaviour and activities. The objectives of this paper are to identify the characters of the urban environment that make safety street to women and to establish the characteristics of safe urban street environment that influenced the women social behaviour.

\subsection{Literature Review}

The urbanization process has led to urban population growth, therefore need more attention concerning the quality of urban open spaces that fulfil the users' needs. Most of the public spaces, including streets in the CBD area not reflecting the needs of user's behaviour and activities. Most of the Malaysian planners and urban designers failed to provide a broader range of activities specifically for women safety, appropriate for the climatic, physical, social and economic circumstances of Malaysian cities. Human dimension has been overlooked and not seriously addressed in urban design compared to other issues, such as accommodating the increase of cars in urban areas (Rahman et al., 2015, 2018: Gehl, 2010).

The role of human aspects is established as an essential framework for a good urban street. Human beings are the most moveable objects that need a variety of outdoor activities, including trade, recreation and urban life in the street (Mehta, 2009). If the street is not designed for people, it will become a place that breeds crime due to the lack of human surveillance. Gehl (2010) argued that the categories of outdoor spaces are influenced by the quality and the character of the outdoor space and the activities and functions will be developed when the conditions of the space are improved. The fear of crime should be reduced through urban design, lighting and visible presence of the police and other uniformed officials.

Gehl (2010) stressed that activities in outdoor spaces are influenced by the quality and the character of the outdoor space. Researchers have studied the relationship between the environment and human behaviour for decades to understand what attracts people to public spaces and support social activities. Their findings point to characteristics of the environment that are place-based and ones that are people-based; that is, some are a result of the features of the physical environment, and others, a consequence of human actions and management (Mehta, 2013). This statement is supported by Lynch (1984), the physical features and appearance play an important role in making places more legible to the users which can be identified, organized and navigated by people with identifiable layout and clarity of the cityscape in terms of its physical form and function. Outdoor activities in public space can be divided into three categories: necessary activities (going to school or work, waiting for 
a bus or a person, shopping, etc.), optional activities such as taking a walk, standing around enjoying life, or sitting) and social activities such as children at play, greeting and conversation, seeing and hearing other people (Gehl, 2010; Rahman et al., 2018). Place physical and functional qualities influence the degree of dependency on and attachment to place as a platform for activities and social interaction (Ujang, 2012). However, in Malaysia cities, identification of the physical (functional) attributes and characteristics of a place that contribute to place attachment have not been adequately addressed (Ujang, 2012). According to Ujang (2012), place dependence is associated with the perceived strength of association between a person and specific place which is related to the quality of the current place and the quality of other substitute places that are comparable to the present place. Ujang (2012) also suggested that the best and responsive streets are those that are physically, economically and socially diverse.

Another dimension that shows differences in the use and perception of the open spaces is gender. Previous studies in street design found that there is a significant difference between the responses obtained from respondents from different genders (Sideris, 1995; Sisiopiku et al., 2003). In the research by Sideris (1995), it was found that women are the minority group that use urban space. She also found that more men than women seemed to enjoy the social role of the parks (Sideris, 1995). Women's perceptions and use of urban space are restricted by the logic of social dominance and safety (Whyte, 1980; Tonkiss, 2005). Women always feel discriminating and sensitive to annoyances, even though in public places (Whyte, 1980). Perception of safety is a common concern and a reality in all urban spaces that cannot be denied as one of the factors in comfort (Rahman et al., 2015, 2016, 2018). Safety refers to streets that enable people to use, enjoy and move around the outside environment without fear of tripping or falling, being run- over or being attacked (Jacobs, 1961). In respect to streets, based on previous scholars, safety mostly relates to crime and traffic safety. Much of the literature shows that, across many cultures and time, women, children, older groups of people and people with disability were the groups that have most concerns and have been threatened in public spaces, which makes them feel less safe and comfortable to use the space. In this paper, the significance of the attribute and elements that contribute to safety to the women in Malaysia context will be evaluated.

\subsection{Methodology}

The street environment is examined using both quantitative and qualitative analysis. A triangulation method and cross-analysis between different techniques and literature are reviewed to identify the problems relating to urban street design and women behaviour. A sample survey is conducted in a selected urban area in Jalan Tuanku Abdul Rahman (JTAR), Kuala Lumpur. An interview with a smaller group of urban users is conducted to probe on issues highlighted in the survey to determine the influence of the outdoor environment on the women behaviour. This technique will photograph and map the people to their activities and behaviour. This research will contribute to the knowledge of both safe cities and women behaviour studies. A total of 150 female respondents participated in this survey. The questionnaires survey conducted the respondents were broadly divided into two types of the 
user which are daily user group and occasional group.

In achieving the objectives, all the data received from the survey were analysed using SPSS. All the data from the survey were then converted into a data file, which contains the data of all respondents. The frequencies of all the variables from the data are shown in this sub-section, the cross-tabulation between variables was used to look at any relationships between variables. The results from the interviews, physical observation and activities observation were used to support the results revealed from the questionnaire surveys. This section will discuss the factors that contribute to a user-friendly urban commercial street, the user's actual activities and uses on the street, the reasons and the main attraction, how they use the street and how the survey data is triangulated. Triangulations were made within and between other data from observation of the physical characteristics and activities on the street, interviews and from previous research in the literature review.

\subsection{Findings and Discussion}

This section presents the findings of the analysis of data associated with identifying the characters of the urban environment that make safety street to women and establishing the characteristics of safe urban street environment that influenced the women's social behaviour. In the analysis, results from the survey on the qualities appraisal were triangulated to further inform the results from the survey, interviews and observations.

\subsection{The characters of the urban environment that make safety street to women} In respect to safety and security, it shows that the occasional group has a more positive response than others; however, the variation between the three groups is slightly different. This also indicates that the perceptions towards the qualities of the street are related to the type of user activity on the street; the daily user group are the group that is generally involved with necessary activities while the occasional group are involved with optional activities. This is parallel with the ideas of Gehl (2010) that most of the daily users are in the group that relates to necessary activities. Therefore, we can relate that the reasons for using the street may affect their perceptions and preferences concerning the street. The overall mean value under safety and security attributes shows that it is a very significant factor that makes a user-friendly urban commercial street. The following section discusses the characteristics that define the safety and security of the street. This analysis shows that the lower the scale of the result, the more significant the quality. The scale of 1.21-1.89 of the attributes shows that safety and security qualities are essential to encourage the use of the street in respect of JTAR (see Table 1). This finding is parallel with Burton et al. (2006) who found that safety is an essential characteristic of street life. This is also supported by Gehl (2010), who noted that the feeling of safety is vital to attract people to use the city space and that people themselves make the city more inviting and safer in terms of both experienced and perceived security. 
Table 1. Degree of safety and security attributes based on mean values on the most important attributes

\begin{tabular}{|c|c|c|c|c|c|}
\hline & Safety qualities & Occasional & Daily & Non-user & Mean Value \\
\hline$a$ & $\begin{array}{l}\text { Presence of security officials and } \\
\text { police patrols }\end{array}$ & 1.19 & 1.24 & 1.19 & 1.21 \\
\hline$b$ & Low crime statistics & 1.25 & 1.44 & 1.25 & 1.34 \\
\hline c & Free of accidents & 1.26 & 1.39 & 1.35 & 1.34 \\
\hline$d$ & Safe crossing devices & 1.36 & 1.39 & 1.46 & 1.39 \\
\hline e & $\begin{array}{l}\text { Safe environment for elderly, } \\
\text { disabled and children }\end{array}$ & 1.42 & 1.45 & 1.32 & 1.41 \\
\hline$f$ & $\begin{array}{l}\text { Free of presence of anti-social } \\
\text { behaviour }\end{array}$ & 1.36 & 1.47 & 1.37 & 1.41 \\
\hline$g$ & No graffiti and vandalism & 1.39 & 1.51 & 1.49 & 1.47 \\
\hline $\mathrm{h}$ & Low traffic flow and speed & 1.58 & 1.51 & 1.74 & 1.57 \\
\hline i & Presence of people & 1.74 & 1.74 & 1.93 & 1.77 \\
\hline j & Presence of activities & 1.76 & 1.72 & 1.98 & 1.78 \\
\hline k & Full of activities day and night & 1.91 & 1.78 & 2.18 & 1.89 \\
\hline & $\begin{array}{l}\text { Mean Value } \\
\text { Response format } \\
1=\text { strongly important } \\
4=\text { strongly unimportant }\end{array}$ & 1.47 & 1.51 & 1.57 & 1.50 \\
\hline
\end{tabular}

(Source: Authors)

The results from Table 1 also show that the occasional users perceived the importance of the presence of security and police officers, free of accidents, low crime statistics and free from the presence of anti-social behaviour more than other attributes; this relates to their feeling of safety for conducting activities on the street (Table 1). The daily group perceive the importance of safety and security attributes a bit less than the other groups. This may relate to their sense of belonging to the place and familiarity, which contributes to the feeling of safety in that place. The safety and security factor may affect how people use the street, and the sense of safety and security in places can make people use the street comfortably. People may act differently when they feel unsafe when using the area or try to avoid using it altogether. The results indicate that $60.2 \%$ of the users in JTAR do not feel safe to use the street alone (Table 1). This is supported by the results from the survey based on how they use the street, in which most of the users use the street with their peers. Most of the users $(43.1 \%)$ come to this place with their peers, $31.9 \%$ like to come here alone followed by with their family $12.9 \%$ and the remaining $12.1 \%$ as couples. The main reason mentioned in the study for preferring to come with their peers is because they feel more comfortable, safer, and it facilitates their leisure and discussion needs. The respondents were also asked about the reasons they do not feel like using the street alone. The four main reasons mentioned in the survey were, there are a lot of migrants in that area (31.6\%), high crime rate (20.8), lack of supervision by police (12.2\%) and the environment of the street is too crowded( $10.5 \%)$ with traffic and people (Figure 1).

Figure 1 indicates that the main reason for women not feeling safe using the street alone is due to the presence of immigrants. This is reflected by the comment of respondent no 2: "Normally I try to avoid walking alone in the area with fewer people and the area with lots of immigrants, 
especially back lanes and the Chow Kit area because it makes me feel unsafe and out of place."

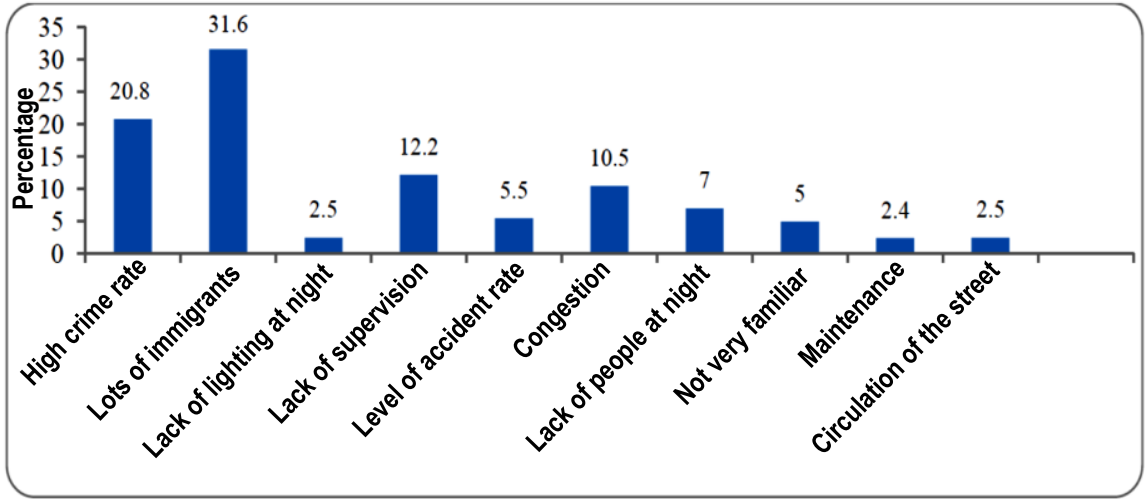

Figure 1: Reasons for not feeling safe

(Source: Authors)

Conflicts often arise between different groups of people in the street. The conflicts arise between bourgeois public order and counter-public (immigrants), various working-class ethnic groups and others who claim the sidewalk for economic, social and political activities in various ways and at various times. Based on the interviews, many people consider their presence in the city as problematic (Ehrenfeucht et al.,2010). The presence of immigrants in many locations also creates conflicts with other public groups (Krupat, 1985). The other main issues indicated in the survey (Figure 1); concerning the reasons that make the user feel unsafe to use the street include the high crime rate and lack of supervision by police. It is shown that the factors relating to the activities, such as the presence of activities day and night do not have a significant rate for safety and security aspects compared to the other attributes.

\subsection{Attributes defining the safety and security of the street}

\section{a) The presence of police surveillance}

The results of the survey of the safety and security attributes of the street have indicated that the presence of security officers and police patrols are the most cited important attribute that contributes to the feeling of safety and security on the street. The result of the survey shows that based on the three groups of users, the occasional and non-user group strongly expressed about this matter compared to the daily users. The daily group are much more familiar with the street and have been engaged with the street for a long time, which makes them feel safer and more attached to the street. Based on the result on the survey it shows that one of the reasons users do not feel safe using JTAR alone is because of the lack of supervision by security officers and police (Figure 1). The most interesting point to emerge from the result is that the results from this survey were supported with most of the previous 
authors who noted that natural surveillance is one of the critical factors in contributing to the feeling of security and safety on the street, as Jacobs $(1961, p .40)$ stressed in her book:

"The first thing to understand is that the public peace - the sidewalk and street peace -of cities is not kept primarily by the police, necessary as police are. It is kept primarily by an intricate, most unconscious, network of voluntary controls and standards among the people themselves and enforced by the users themselves".

However, for some people, the presence of police surveillance on the street gives the kind of feeling of uncomfortable due to thinking that their behaviour and activities been watched by them. This is reflected by the comment of respondent no. 8":

"I feel uncomfortable; automatically when I see police around, I feel that they are looking for our fault because that the nature of their job looking for peoples' faults".

Based on the observations on-site, increasing pedestrian visibility by placing windows, doors and "eyes on the street" can increase the pedestrian's sense of security on the street and at the same time increase the number of people using that place. This was supported by most of the respondents in the interview survey. Daily users felt more secure in using the street without the presence of police surveillance due to the familiarity and greater attachment and the sense of belonging to the street, while for the occasional group, some of them feel more secure and safe when they see the presence of police on the street.

\section{b) Free of accidents and low crime statistics}

Many studies have repeatedly found that the main criteria for good open spaces are safe from criminals and free of accidents. The finding in this research also highlighted that 'free of accidents' and 'low crime statistics' are among the most important attributes that contribute to the feeling of safety to use the street. In respect of crimes related to the street, snatch thefts constitute $12 \%$ of the overall crimes that frequently occur in places like bus stops, commuter stations and along main roads. Based on observation on site, it was observed that the conflict between pedestrians and motor vehicles is more crucial compared to crime issues. In the case of JTAR, people walking along the streets can be seen by drivers and other pedestrians; however, the traffic speeding along causes the pedestrians to feel unsafe. The results of the survey and interviews show that most of the women are concerned about the segregation of pedestrians and vehicular traffic for safety purposes. Based on observation, there is also no buffer or separation between the walkway and the road. Even though the pedestrians already have their own "walking space" by buffering pedestrians from passing cars, especially in areas with a narrow walking space will increase the feeling of security to the users.

In summary, we can conclude that safety from crime and accidents is paramount and encourages people to use the street and makes the street-friendly to them. This is in line with Jacobs (1996), who stressed that safety refers to the streets that enable the people to use, enjoy and move around the outside environment without fear of crime and fear of tripping or falling. 

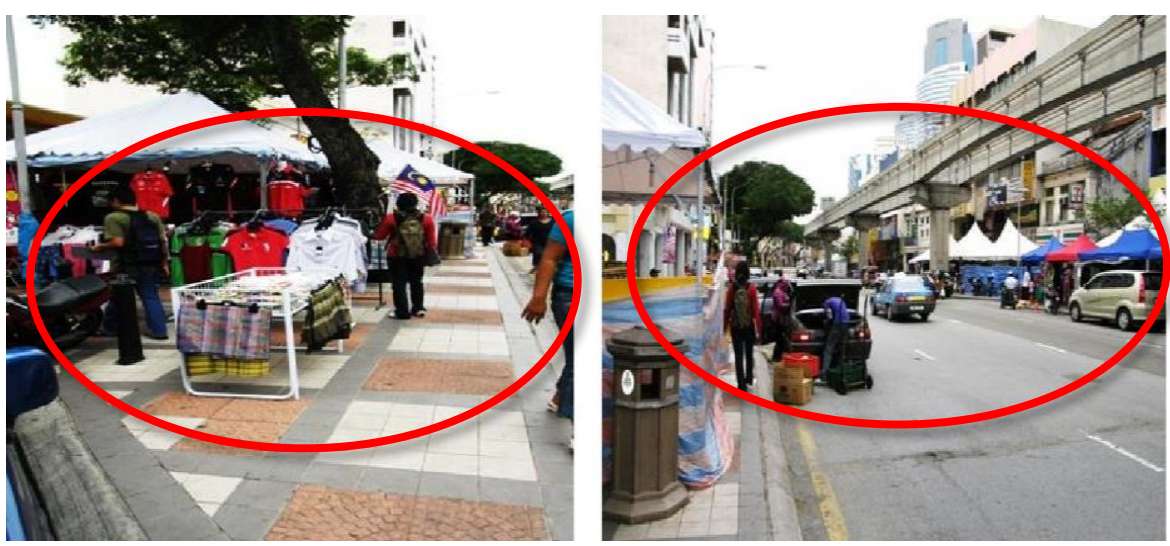

Figure 2: Street vendors operate on the sidewalk causing people to walk in the danger zone

(Source: Authors)

\section{c) Safe crossing devices}

The findings from the survey indicate that safe crossing devices are one of the most important attributes that contribute to a safe street. In JTAR, two types of pedestrian crossing devices are provided overhead pedestrian crossings and zebra crossings with traffic lights (Figure 3).
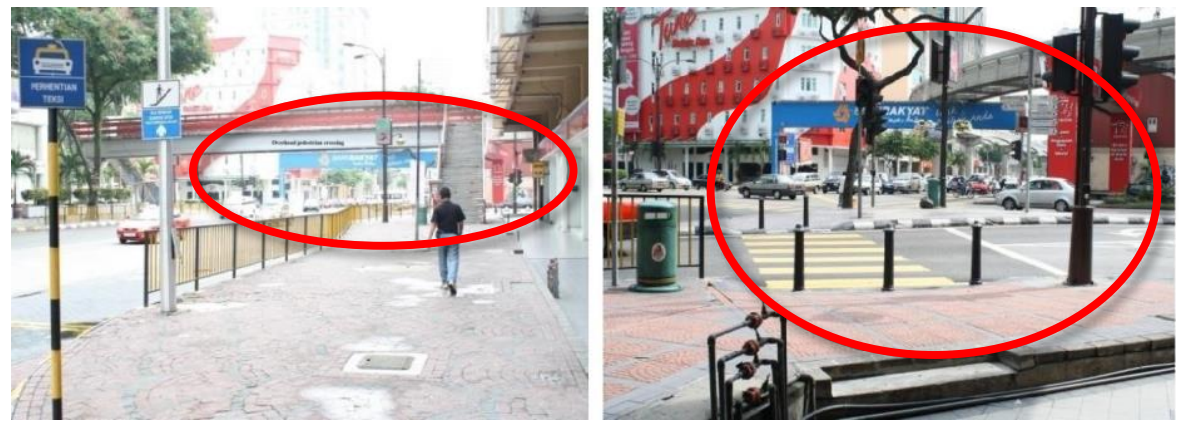

Figure 3: Types of crossing device along Jalan Tuanku Abdul Rahman (Source: Authors)

It was observed that the presence of safe crossing devices is another crucial attribute in supporting the feeling of safety and security in using the street. The pedestrian crossing is significant for pedestrian safety to cross the street, especially in an area that is busy with traffics. This is because most of them use the street for shopping purposes and bring many bags and sometimes come with their family. It was observed that there are some areas along the study street that not provided with pedestrian crossing where it supposed to according to Malaysian Standard 1331(2003), at busy shopping areas pedestrian crossing where it should 
be provided.

The result from observation in JTAR found that most of the users used the zebra crossing compared to the overhead crossing. Based on observation, the people prefer to cross the road illegally rather than use the crossings provided. This is due to many factors, the first reason being the width of the street. The wider the street, the longer it will take to cross, therefore, the longer pedestrians will be exposed to vehicular traffic. In the Chow Kit area, the crossing distance is about 15 metres across. The allocated time to cross is not sufficient for certain groups of users, especially when heavily loaded with shopping. It is even worse when some of the motorists and especially bikers, do not follow the stop signal. This is supported by the comments from the respondent's no. 1:

"it's hazardous there, even though pedestrian crossings are provided and traffic lights to help pedestrians to cross the street I am still not very confident of crossing because the drivers love to speed, and sometimes they do not stop when the traffic light turns red" (Respondent 1).

Another reason is that the overhead crossing is not suitable for women with mobility issues, such as pregnant women, women with shopping bags or strollers and older people. It is impossible for these groups to climb up the staircase with no other supportive facilities provided, such as a ramp or escalator (Figure 4). The overhead crossing is also away from street level and lacks pedestrian surveillance, which contributes to the feeling of insecurity to the pedestrians. Putting spaces away from the street level, like sunken spaces or urban rooftop spaces is not convincing in terms of safety (Rahman et al., 2018; Whyte,1980).

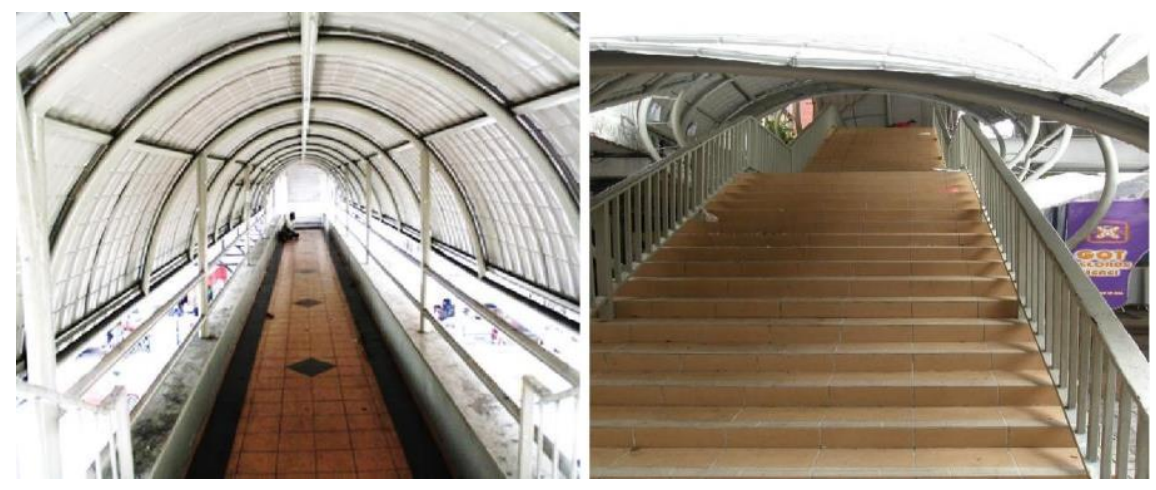

Figure 4: Overhead crossing in Jalan Tuanku Abdul Rahman that is isolated from the pedestrian route (Source: Authors)

\section{e) Free of the presence of anti-social behaviour}

Free of the presence of anti-social behaviour attributes on the street is closely linked with the feeling of safety and security in the physical and physiological sense. The results from the observations in JTAR show that people tend to avoid using or passing through spaces that have people acting anti-socially. This is supported by the findings from the interviews during which it was expressed that they usually avoid walking through the Chow Kit area or using 
that area due to the feeling of being unsafe and insecure. In the Chow Kit area, many immigrants make users feel that this is not the place to be (Figure 5).
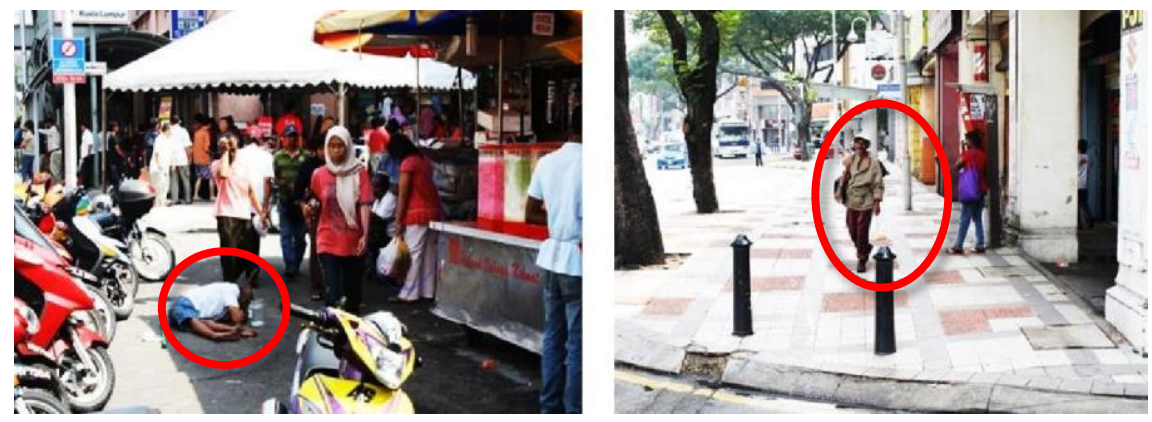

Figure 5: The presence of undesirable people that reflect the feeling of insecurity and being uncomfortable in Jalan Tuanku Abdul Rahman

(Source: Authors)

Based on observations on site, graffiti and loitering groups make other groups of users feel uncomfortable. Street users, especially women, feel insecure to use the street when there are groups of youngsters loitering along the street. The presence of immigrants and beggars, especially in the Chow Kit area also gives the user the feeling of insecurity. According to respondent no. 2; "I don't have the confidence to use JTAR alone because there are many immigrants here that make me feel it is not my place and unsafe, and sometimes also our local people don't even bother if we face any problem there."

\subsection{Conclusion}

This paper identifies the characters of the urban street that make streets safe to women and to establish the characteristics of a good urban street environment that influenced women social behaviour. It was found that there is a significant difference between daily groups of women and occasional of women with characters of the urban environment that make safety street. Sense of belonging to the place and familiarity contributes to the feeling of safety in that place. In this research, the most significant attributes defining the safety and security of the street for women are 'free of accidents and low crime statistics ', 'the presence of police surveillance', 'safe crossing devices' and 'free of the presence of anti-social behaviour'. This research will contribute to the knowledge of both safe cities and women behaviour studies. Findings from this research will provide new insights to the human-environment theories on a safe street design that will promote positive social behaviour in Malaysia city. The statistical data and result from the data analysis will be an indication to explore further possibilities for developing guidelines for the future planning and design of urban commercial streets that promote safe urban environment. This research will contribute towards a safe urban community which will provide a high-quality urban design with a good urban environment and dynamic economic activities. 


\section{Acknowledgement}

The authors are grateful to the Ministry of Higher Education (Malaysia) and Universiti Teknologi MARA for sponsoring this research. The authors would also like to thank the following organisations; Dewan Bandaraya Kuala Lumpur (DBKL), Jabatan Perancangan Bandar dan Desa (JPBD), Assoc. of Malaysian Environment-Behaviour Researchers (AMER) and Assoc. of Behavioural Researchers on Asians (ABRA) for their contributions in the completion of this research.

\section{References}

Burton, E., \& Mitchell, L. (2006). Inclusive Urban Design: Streets for life. UK: Architectural Press.

Davies, L. (2000). Urban Design Compendium. English Partnership UK.

Ehrenfeucht, R. \& Loukaitou-Sideris, A. (2010). Planning Urban Sidewalks: Infrastructure, Daily Life and Destinations. Journal of Urban Design, 14( 4), 459-471.

Gehl, J. (2010). Cities for People. London: Island Press.

Jacobs, A. B. (1996). Great Streets. Cambridge, Massachusetts: The MIT Press.

Krupart, E. (1985). People in Cities: The Urban Environment and its Effects. New York: Cambridge University Press.

Loukaitou-Sideris, A. (1995). Urban Form and Social Context: Cultural Differentiation in the Uses of Urban Parks. Journal of Planning Education and Research, 14, 89-102.

Lynch, K., 1984. Good City Form. Cambridge, Massachusetts: The MIT Press.

Mehta, V. (2009). Look Closely and You Will See, Listen Carefully and You Will Hear: Urban Design and Social Interaction on Streets. Journal of Urban Design, 14(1), 29-64.

Mehta, V. (2013). The Street: A Quintessential Social Public Space. Routledge.

Rahman, N. A., Ghani, I., Bahaluddin, A., \& Hussain, N. H. (2018). Creating Good Social Behaviour through Userfriendly Street Environment. Asian Journal of Quality of Life (AjQoL), 3(12), 51-60.

Rahman, N. A., Md Sakip, S. R., \& Mat Nayan, N. (2018). A User-Friendly Shopping Street. Asian Journal of Quality of Life (AjQoL), 3(10), 1-8.

Rahman, N. A., Md Sakip, S. R., \& Mat Nayan, N. (2016). Physical Qualities and Activities for a User-friendly Shopping Street in the Context of a Malaysian City. Procedia - Social and Behavioural Sciences, 222, 196-202.

Rahman, N. A., Shamsuddin, S., \& Ghani, I. (2018). Factors Determining Usability of the Streets. Asian Journal of Behavioural Studies (AjBeS), 3(12), 73-80.

Rahman, N. A., Shamsuddin, S., \& Ghani, I. (2015). What Makes People Use the Street?: Towards a Liveable Urban Environment in Kuala Lumpur City Centre. Procedia - Social and Behavioural Sciences, 170, 624-632.

SIRIM, 1993. MS 1331:1993- Code of Practice for Access for Disabled People Outside Buildings (1993): Department of Standards Malaysia. 
Abdul Rahman, N., et.al. / Asian Journal of Behavioural Studies (AjBeS), 4(17) Sep/Dec 2019 (pp.53-64)

Sisiopiku, V. P. \& AKin, D. (2003). Pedestrian Behaviors at and Perceptions Towards Various Pedestrian Facilities: An Examination Based on Observation and Survey Data, Transportation Research Part F 6 (2003), 249-274.

Tonkiss, F. (2005). Space, the City and Social Theory: Social Relations and Urban Forms. UK: Polity Press.

Ujang. N (2012). Place Attachment and Continuity of Urban Place Identity. Procedia-Social and Behavioural Sciences, 49, 156-167.

Whyte, W. H. (1980). The Social Life of Small Urban Spaces. Washington, D.C.: The Conservation Foundation. Bishop, K., \& Said, I., (2017). Challenges of Participatory Qualitative Research in a Malaysian and Australian Hospital. Asian Journal of Environment-Behaviour Studies, 2(4), 1-11. 